\title{
BENCHMARKING IN HIGHER EDUCATION
}

\author{
Jerzy Woźnicki, Polish Rectors Foundation, Górnośląska 14, 00-432 Warszawa, \\ +48226210972, frpfund@mbox.pw.edu.pl, marzenagemb@wp.pl
}

\author{
Mariusz Luterek, PhD, Institute of Knowledge Society, Górnośląska 14, \\ 00-432 Warszawa, \\ +48226210972, Mariusz.luterek@gmail.com
}

\section{Iryna Degtyarova, PhD, Oles Honchar Dnipropetrovsk National University, Haharin Avenue, 72, 49010 Dnipropetrovsk, Ukraine, +380678640410, irenkadnepr@ukr.net}

\begin{abstract}
Purpose: Nowadays higher education (HE) meets a number of challenges, global, systemic and local: international competition, competition between public and non-public sectors, competition inside the sectors, growing expectations of the market, population decline, insufficient funding, etc. Higher education institutions (HEIs) must be effective to succeed in research, to provide best academic practices and high quality of studies.

The purpose of the paper is to present the concepts and results of Program "Benchmarking in HE" conducted by the Polish Rectors Foundation.

Methodology: Benchmarking is crucial for the whole HE system as the method of searching for best practices that enables the achievement of the best results by learning from the others, using their experience and collaborating with them. To be appropriate to HE system, research methodology includes external benchmarking and benchmarking of processes. Also open method is used, so the project beneficiary is the entire system of Polish HE.

The benchmarking system applied by PRF monitors a wide range of quality and efficiency characteristics of Polish HEIs.

Findings: Research program "Benchmarking in HE" studies and evaluates Polish HEIs performance through comparative institutional learning approach providing them with crucial information, promoting wider environmental networking, increasing efficiency and improving their international competitiveness, etc. The benchmarking research program consisted of 5 projects that can be grouped into studies aspects (e-learning, quality assurance systems, studies flexibility, National Qualifications based on European Qualification Framework and managerial ones (university governance). Each project results in a summary report providing not only analytical survey, but also practical recommendations.

Value: Benchmarking being a part of good governance principle in HE is valuable research both in Poland and internationally (e.g. European Benchmarking Initiative). Our benchmarking program boosts quality of Polish HE system, university strategic profiling and performance improving for ensuring the life-long-learning principles in Poland.
\end{abstract}




\section{PURPOSE}

Nowadays higher education (HE) meets a number of challenges at global, local and systemic level: international competition, convergence of public and non-public sectors, competition inside the sectors, growing expectations of the labour market, population decline, insufficient funding, etc. All those factors are becoming increasingly important catalysts for the situation in higher education. Their impacts will depend on the performance of the HEIs; the international position and prestige may be a prerequisite for the successful acquisition candidates and entering the local market with various educational offers.

The ongoing implementation of the Bologna Process in Europe, including Poland, prompts comparisons with international competitors and efforts to match their standards, while also opening up to the European market to Polish higher education institutions, whether public or non-public, especially the more renowned ones and those which are already gearing up towards European expansion. The competitiveness of Polish HEIs should be significantly boosted by the comparable quality of their curricula contents, providing best academic practices and high quality of studies, comparable levels of education process achieved thanks to ECTS, diploma supplements and evaluation performed with modern management tools [1].

Due to external dynamic changes in the academic environment the efficiency of the adjustment processes in tertiary education requires, on the one hand, to provide the autonomy of higher education institutions in order to ensure the ability to solve problems effectively on their own, and on the other hand, to equip the minister responsible for higher education with tools enabling him to regulate and supervise the higher education system. Both of these conditions are now met in Poland by the Act on Higher Education [2].

However, it is essential to provide rectors with professionally compiled and maximally comprehensive governance-related information creating more opportunities for successful development of the HEIs in competitive higher education environment. Taking into account the trends and processes at the international level, it is expected that the academic institutions - in order to be successful in the European higher education and research area - will have to be both slow in changes in some areas, and dynamic and profound in the others. The harmonization of such activities in higher education is a challenge for university managers.

One of the ways ensuring evaluation of university performance, diagnosis of the institutional strengths and weaknesses, priorities and specific targets definition as well as being a tool for boosting the university competitiveness is the use of benchmarking methods in higher education.

It's worth to mention that academic benchmarking is declared a strategic tool for university management in a number of European documents:

- Document of European University Association - The Lisbon Declaration - Europe's Universities beyond 2010: Diversity with a Common Purpose: Governments are urged to benchmark progress against target levels set in relation to both autonomy and funding of universities. Universities will strive to reinforce further leadership and strengthen professional management.

- Communique of Ministers responsible for Higher Education of European countries London Communique: Towards the European Higher Education Area: responding to the 


\section{Proceedings of 2013 International Conference on}

TIM Technology Innovation and Industrial Management

29-31 May 2013, Phuket, Thailand

challenges in a globalised world: Priorities for 2009: (...) Data collection: we recognize the need to improve the availability of data on both mobility and the social dimension across all the countries participating in the Bologna Process.

Benchmarking has emerged in the sphere of business and it has been widely used in industry, finance, transport, retail, services, etc. aimed at quality improvement, discovering work optimizing ways. In Europe, the use of benchmarking as a tool for improving performance both in the private and public sectors has also been supported by the European Commission (DG Enterprise) for more than ten years Benchmarking initiatives were started in the late 1990s such as a benchmarking group on competitiveness, a European Benchmarking Forum and a High level Group on Benchmarking. A Benchmarking Coordination Centre was also established to provide support with data and resources. In 1998 the Great Britain Commonwealth Higher Education Management Service published a research paper „Benchmarking in Higher Education” having particular reference to the higher education of the United Kingdom, Europe, Australia, and North America.

The first EU-funded benchmarking project "European Benchmarking Initiative in Higher Education" was conducted in 2006-2010 and implemented by four partner organizations: the European Centre for Strategic Management of Universities (ESMU), the Centre for Higher Education Development (CHE), the International Centre for Higher Education Management (ICHEM), University of Bath and the Institute of Education (IoE), University of London. The Initiative was designed to help modernize higher education management and to promote the attractiveness of European higher education. The European Commission's view was the benchmarking would be a modern management tool to progress with institutional reforms, increased operational efficiency and the capability for innovative changes to adapt to new challenges in their environment [3].

In the framework of this EU-project a number of papers and books were published, including „Practical guide on Benchmarking in European Higher Education” (2008), and „A University Benchmarking Handbook. Benchmarking in European Higher Education” (2010).

In 2010 the new on-line benchmarking research project named "Global Research Benchmarking System" (GRBS) was started by United Nations University International Institute for Software Technology and the Centre for Measuring University Performance. In 2012 the research covered higher education establishments in Asia-Pacific, the USA, Canada and Europe (27 EU-member states plus Norway and Switzerland).

Following to European trends, benchmarking researches on the national level were held in some European countries and in the USA, Australia, etc. In Poland for the first time benchmarking in higher education on broader scale was used by Polish Rectors Foundation $(\mathrm{PRF})^{1}$ within the Program "Benchmarking in higher education", which is being carried out since 2007. Thus, the purpose of this paper is to present the concepts and results of research PRF program mentioned above in the area of education and training.

\footnotetext{
${ }^{1}$ Polish Rectors Foundation working together with Institute of Knowledge Society has been evaluated by Polish National Rectors Conference (CRASP) as a leading think-tank in research into HE in Poland.
} 


\section{METHODOLOGY}

Benchmarking is crucial for the whole HE system as the method of searching for best practices that enables the achievement of the best results by learning from others and use their experience. Benchmarking is based primarily on the identification of best practices and their creative adaptation, which excludes the possibility of copying. The direct purpose of this method include: better processes identification, comparing with others, identifying strengths and weaknesses on the background pattern, learning from others, and boosting working practices. Indirect objectives of benchmarking are development of management skills, overcoming reluctance to ideas generated outside the institution, increase of students' satisfaction and competitive advantage [4].

Based on the criteria of subject benchmarking can be subdivided into internal and external (which can be competitive and general). Internal benchmarking is used in large organizations with complex organizational structure. Due to the specificity of the "Benchmarking in higher education" Project, we have selected the method of external benchmarking, comparing different higher education institutions.

From the point of view of the goal criteria, benchmarking can be: of results (comparison of the results gained in any subject sphere), processes (comparing procedures and processes occurring in the institution), and strategic (comparing operations at the strategic level). In the Program "Benchmarking in higher education" we are using benchmarking of processes.

Benchmarking can also be carried out using two methods: closed and open one. Closed method is used for a specific group of entities, often paying a fee for the opportunity to participate in the survey, and aims to increase their individual competitiveness. This means that beneficiaries of the benchmarking are only the organisations participating in the survey (and only them have access to its results). In our Program we are using the open method. In this case, the university group voluntarily participates in the research, and are not subject to any fees. Findings of the survey are publicly available, however in anonymised version. As a result, the main beneficiary of the project is the entire system of higher education, and the research is carried out to improve its competitiveness (and not only selected organisations).

The benchmarking system monitors Polish higher education institutions based on a variety of criteria. A wide range of relevant quality and effectiveness characteristics are taken into account, having to do with the current state of the institutions, their tasks and resources, strategy and competitiveness, performance and development perspectives, both domestically and in relation to European higher education institutions [5-7].

Data are gathered through all available channels of information. Specifically, the data are taken from publications by relevant Polish and foreign institutions, from online sources as well as from materials provided by HEIs based on special agreements relating to the benchmarking system $[8,9]$

Research carried out within the program "Benchmarking in higher education" is conducted with the use of questionnaires available electronically for the respondents in system KWERO, developed specifically for the Program. This system includes a central repository of data, which holds all the data needed to carry out the benchmarking process. 
The surveying system KWERO allows differentiation of applications concerning many different issues: publishing surveys, further working with them, completing survey by proper respondents, surveys verifications by participants of steering committee experts, and so on.

There are 4 types of applications in the system:

- the client application - allows access to the database (filling in questionnaires, review of results, etc.);

- the analyst application - allows to define questionnaires, export of data and support the process of filling questionnaires;

- the administrator application - manages users access rights;

- the content manager application that allows publishing new content and structuring the site.

Access to specific functionalities of the system is determined on the basis of a system positions (roles) and permissions. The system differentiates several groups of users with different activity rights (e.g. users, analysts, administrators).

Data input into the system is mainly held by filling in the electronic users surveys and also by placing the data available from external sources. Completed questionnaires are stored in the database after approval by a data entry supervisor [10].

\section{FINDINGS}

Research program „Benchmarking in HE” studies and evaluates Polish HEIs performance through comparative institutional learning approach providing them with crucial information, promoting wider environmental networking, increasing efficiency and improving their international competitiveness, etc.

Therefore the program aims are to develop and launch a benchmarking system providing public and non-public higher education institutions as well as other interested organizations (such as institutions conducting rankings) with advanced governance-relating information. It is also important to respect the principle of access confidentiality, allowing to detect the factors affecting the competitiveness of stakeholders: universities and their associations, consortia, networks, universities, etc. with regard to international relations.

The benchmarking research program consists of 5 projects that can be grouped into 2 types:

Group 1. Studies issues:

1) Benchmarking of e-learning processes (31 participating universities)

2) Benchmarking of processes related to internal quality assurance systems (33 participating universities),

3) Benchmarking of processes of studies flexibility (32 participating education establishments),

4) Benchmarking of processes related to the implementation of the National Qualifications Framework (48 participating universities).

Group 2. Managerial aspects:

1) Benchmarking of process of university governance to improve productivity and competitiveness - management control (37 participating education establishments) 
Each project results in a summary report providing not only analytical results but also practical appliances and recommendations.

In this paper we will discuss some findings from benchmarking of processes related to internal quality assurance systems and benchmarking of processes of studies flexibility.

\section{Benchmarking of internal quality assurance systems}

\subsection{Context and goals}

The Bologna Process, which from the beginning at its foundation has been closely associated with the issue of lifelong learning, entered a new stage with the adoption of the Recommendation of The European Parliament and of the Council of 23 April 2008 on the establishment of the European Qualifications Framework for life long learning (EQF).

The formal objective of the EQF is to establish a common European system of relating of the various countries' national education (qualification) systems to a common reference framework and accordingly facilitating mobility between them. EQF has revolutionary significance in the word „qualification" that means that the factor for comparing national systems will not be the input criteria, describing the content of the curriculum and requirements for staff and a learning process, so-called learning outcomes: the scope of actually acquired knowledge, skills, and so called soft skills - attitudes, the acquisition of which can be associated with a given level of education. Such approach obviously means a huge change in the way providing research and information on the quality of education, and the implementation of appropriate quality assurance system is essential for entry of the university into the qualifications framework system.

The research related to the advancement of quality assurance and reasons for application of this approach was of innovative character. The main difficulty stemmed from the fact that structured set of rules for the creation and operation of such systems were not refined in Poland. The authors faced with a challenging task of measuring the level of advancement of a very diverse set of internal quality assurance systems in HEIs, implemented at different times, focused on achieving different goals and, what is crucial, usually introduced without awareness or taking into account of the requirements of the adopted by Poland obligations related to the implementation of the Bologna Process.

\subsection{Results}

The results of this research, conducted in 2008, showed that all Polish universities have established the rules (e.g. in the Statutes or Regulations) on the number of learning groups, but at the same time, however, only $64 \%$ of institutions regulate the ratio of students to teachers, and $85.7 \%$ - the number of graduates conducted per a promoter in a given academic year. Particular procedures were also introduced defining the bases that are periodically reviewed and changed (93\% of responses).

It's interesting, that $14 \%$ of institutions did not provide rules on the form of a thesis (monographic, experimental, etc.), and 7\% - its format. 
All universities have declared conducting systematic surveys of students, analysis of their results and their dissemination of among the university staff. Our research showed, that there are strong differences between HEIs in the form of collecting those data (electronically - only $57 \%$ of universities) and the way in which evaluation sheets are being prepared (again, only $57 \%$ of institutions committed to the professionals). It could be assumed that the HEIs collecting data in the form of paper only, applying unprofessional questionnaires are not able to properly analyze the collected data.

The mass character of contemporary tertiary education makes the need for mechanisms to promote attitudes of special commitment in the teaching process, and their introduction and activity certainly is an important part of quality assurance systems. The responses to the questions on those issues in the survey to a large extent confirm the formal and declarative support for involvement of teaching staff into educational activities. The majority of universities declared that the outcome of the assessment of university professor only to a relatively small extent, influences the final assessment of his work. Universities, however, usually have a system for defining people with the great achievements in teaching.

Both the currently binding legal regulations and the recommendations clearly indicate the need for an external evaluation of the quality assurance system as a condition for the credibility of declarations applied by the universities in particular procedures and mechanisms. By the Law universities in Poland are subjected to control of Polish Accreditation Commission (OAC) . However, as our research shows accreditation obtained outside PAC is not that common. The research revealed that $28.6 \%$ of HEIs had not received any accreditation of this kind, while one of the universities had got 25 accreditations.

Flexible design of study programs and ongoing adjustment to the needs of the wider external environment is one of the most important manifestations of the fulfillment by the university of its social mission. Our results confirmed the generally known fact that Polish universities have small, but still growing flexibility of programs. The deeper analysis, however, considers the case of two or three schools offered a very large number of new fields of study and / or specialty running since the academic year 2005/2006 (from 65 to 69).

All universities participating in the survey responded positively to the questions on the existence of collegiate bodies engaged into the plans and programs of study, and certainly they comply with the truth, because by law the programs and plans of studies conducted at universities are approved by the collegial bodies.

Polish HEIs have already experienced the effects of international competition (significant drain of prospective students), and in the coming years, awareness of the need to build the competitive position not only at the national level but also internationally, will be a necessary condition for their proper functioning. In this context, it is interesting that $42.9 \%$ of HEIs declared that in their development plans and training programs they address the international models and benchmarks.

The next important factor influencing the range of programs and ensuring the quality of its implementation in the coming years will be the new organization of training requirements resulting from the introduction $\mathrm{NQF}$ and the need to ensure the reliability of the declared learning outcomes. The way to achieve this objective and the external acceptance of the 
program offer by candidates for studies and employers, will be transparency of programs and procedures created with the support of external stakeholders. Thus, interesting and relevant to the assessment activities in these areas is the declaration of more than $50 \%$ of universities seeks for such support.

The mobility of students and the internationalization of the university is one of the flagship objectives of the Bologna process. The survey revealed that the universities appreciate the significance of the mobility on both a domestic and international level. In fact, only one HEI reached the rate of 5\% students participating in the exchange programs between universities, but actually low activity of students in terms of participation in international seminars and schools has been observed.

Analyzing the efficiency of search and recruitment of foreign students we found that it is hard to consider all universities participating in the study. Two leaders are the medical HEIs, where the situation is quite different from the universities outside this sector. Our conclusion was, that in the future, with a considerable interest, this kind of HEIs should be analyzed separately. Perhaps it would be advisable in this case further to differentiate the universities in the survey according to their specific sector.

A small number of HEIs declaring their joint diplomas with foreign universities $(28.6 \%)$ confirms the existence of systemic problems in the development of such initiatives.

The proper and wide use of ECTS could be an important indicator of the effectiveness of internal quality assurance processes. As research demonstrated, the majority of Polish universities implemented it on the initial stages, often doing it in formal way and considering as an additional administrative requirement than for process improving and optimizing the curricula and syllabi.

Periodically made assessment of the implementing of the Bologna process indicates more or less satisfactory progress. Remembering that an essential prerequisite for the introduction of two-cycle was promotion of the horizontal and vertical mobility of students and we should highly evaluate the information obtained from the survey, which shows that in many universities introduction of this system significantly created the conditions for such mobility. At the same time, a considerable difference in answers demonstrates the value of such a specific benchmark for positioning university in terms of advancement of the „bolonization” of the education process and thus creating of a new quality.

Taking into account the requirements of university responsibility for the credibility of the declared learning outcomes, the collected information on documenting, monitoring and maintenance of the system and its accessibility for different groups of stakeholders appeared to be valuable. This study was the first attempt to develop a method of determining the measures to enable benchmarking processes related to internal quality assurance systems in higher education. At least a few factors makes this task very difficult. Firstly, the issue of internal quality assurance systems in the majority of Polish universities still remain rather innovation than routine action. Second, the educational institutions have never received external support in developing of such systems. Thirdly, the economic conditions and changing legal framework does not encourage so far to take a long-term and systematic 
measures for the quality of education and support of these activities effort to provide adequate logistical support.

\section{Benchmarking of processes of studies flexibility}

\subsection{Context and goals}

The problem of flexibility of studies was identified as especially interesting during the research conducted in 2008. Furthermore, since 2008 a lot of innovations have been introduced to Polish higher education system, and thus it was important to analyze those changes in the context of previously obtained data.

The flexibility of the studies is based, generally speaking, on the existence within it the certain extent of freedom, allowing its functioning more effectively than its failing. The flexibility of the study system is its gradable feature: in this regard we can speak of a more or less flexibility in the educational system, as well as the elasticising. Flexibility is a multidimensional feature of the education system: determining the degrees of autonomy may in fact appear in different elements of the system.

Studies flexibility means flexibility of the structure of the studies systems, the flexibility of the programs and the course of study. In the first case, the system provides a possibility to choose the level of qualification obtained at the end of the training, the possibility of design learning paths during the study, and the possibility of reducing curriculum.

Studies flexibility must provide a correspondingly wide range of elective subjects individualizing process of studying (for all students) and the procedure to create individual study programs that meet the minimum requirements for learning outcomes. Each subject should be related to the program (the content) and a number of attributes to enable efficient and reliable creation of individual programs. The set of such attributes include:

- number of hours of study divided into various forms of teaching,

- the number of credits assigned,

- a list of required preceding courses (the predecessor),

- a list of similar themed courses (courses are formally equivalent and that can't be chosen alternatively if student passed the exam),

- a form of assessment,

- the nature of the subject from the point of view of curriculum requirements.

The use of thematic classes when formulating the curriculum requirements is that the set of thematic classes, corresponding to the areas of knowledge important from the point of view of the completeness of the education, and then for each of these classes is determined by the minimum number of credits that a student must pass (in addition, may also be a specific set of compulsory subjects in this class). Requirements relating to particular thematic classes are supplemented by a general requirement to obtain a certain number of credits for all years of study together - are summed points assigned to all the classified objects. 
The creation of thematic classes enables students to do the overview of the program, as well as foster:

- definition and consistent use of common terminology and conceptual apparatus of the objects belonging to the same class;

- coordination of the implementation of the content and form of subjects belonging to the same class, in particular the reduction of unintended redundancy (the same content in multiple subjects) and development issues of under-represented in the curriculum;

- the interaction of departments dealing with related subjects, and operating under different organizational units (departments, institutes, HE establishments).

The flexibility of the course of study, which is an important element of the studies flexibility, includes the opportunity to study according to an individual plan of study in subsequent semesters and the possibility of accounting the student achievement (using ECTS) in periods longer than one semester. Both of these solutions help students to adjust their charges in particular study periods, and thus, the pace of study to their needs and abilities.

The main objective of this study was to illustrate the rate of flexibility at the universities operating in early 2011, under the Law on Higher Education in 2005, just before the implementation of the National Qualifications Framework. 32 Participating HEIs sent questionnaires for 208 basic organizational units (mostly - faculties).

\subsection{Results}

As we can see from the data many HEIs do not provide mechanisms to prevent duplication of content of elective subjects. The problem appears to be much larger at the universities $(67 \%)$ than at technical universities (30\%). The lack of such a mechanism could lead to violations of the assignments of credits to student achievement and a waste of financial resources allocated to education.

The vast majority of surveyed HEIs (90\%) allow students to change the direction of the study during the period of their education. The data also showed that the idea of continuing education and lifelong learning (LLL) is still met with limited understanding: other than postgraduate courses and specialized forms of this training are offered by only $7-8 \%$ of the surveyed universities.

The results also allow to assume that the structure of curricula is very often determined by the structure of the teaching staff, the curriculum traditions and / or infrastructure limitations rather than the result of a deeper optimization of learning outcomes that these programs are designed to provide. Only partially the outcomes can be justified by the existence of the education standards and the belief that they are sufficient to systematize the content scheme. The situation is better at technical universities.

One of the most interesting findings was that high percentage of respondents offer training in macro-fields $(9 \%)$, unique $(11 \%)$ or interdisciplinary studies $(10 \%)$. The corresponding figures for the universities $(12 \%, 22 \%$ and $14 \%)$ are significantly higher than for technical institutions $(9 \%, 1 \%$ and $7 \%)$. 
Concerning quality issues, data obtained from answers to questions about the number of ECTS credits for compulsory courses (83\%) and elective ones (14\%) indicate how rigid generally are the 1st-cycle programs offered by the surveyed HEIs. Likewise, the 2nd-cycle study provided by responding universities are only slightly more flexible $(20 \%$ subjects chosen by the students). It is even more surprising, since the studies of 2 nd level are supposed to be integrated into the research and Master thesis' topics should be related in some way to research projects carried out by the academic staff

The curriculum of the 1st-cycle education dedicated to especially gifted students are only slightly more flexible than programs for all students, with the appropriate indicators, designated for universities (16\%) are slightly worse than the average (28\%), and the indices determined for the technical university (29\%) are slightly better. In the case of the second cycle programs, curriculums dedicated especially to gifted students are generally much more flexible (54\% ECTS for elective subjects) than obligatory programs for all students. It turns out, however, that it does not appear to be true in the case universities (only 21\%).

In general our research showed that Polish HEIs are embracing opportunities introduced by implementation of NQF. Since first wave of surveys in 2008 a lot has changes in the area of studies - universities are more used to the idea of Bologna Process, however some of them are more ready for the upcoming reform (especially for the freedom of defining study programs on their own) then others. That's why Polish Rectors Foundation has decided to conducts third wave of surveys - benchmarking of processes related to the implementation of the National Qualifications Framework, which is currently at its final stage.

\section{VALUE}

The Program has provided us strong analytical data and informational characteristics of different HEIs for new findings concerning positioning of Polish HE, more successful grouping, internal and external university rankings. The research discovered a kind of map of HEIs using criteria for quality of studies and quality of management that is critically essential for education as a system and studying process, as well as for the strategy of Life-LongLearning development in Poland.

Benchmarking of $\mathrm{HE}$ in Poland is valuable research both in Poland and internationally. The benchmarking boosts competitiveness of Polish HE system, university strategic profiling and performance improving.

\section{REFERENCES}

1. Woźnicki, J. (2010). 2010-2020 Development Strategy for the Higher Education System. The Academic Community's Proposal. Paper presented at the IMHE General Conference Higher Education in a World Changed Utterly: Doing More with Less, OECD Conference Centre, Paris, France.

2. Woźnicki, J. (2009). The University as an Institution of Public Domain: the Polish Perspective, UNESCO-Cepes, European Centre for Higher Education.

3. Benchmarking in European Higher Education // www.education-benchmarking.org

4. Backgroud, definitions and approaches of benchmarking. European Benchmarking Initiative (EBI) in Higher Education Symposium, Bruksela 2007. 
5. Nazarko, J.; Kuźmicz, K. A.; Szubzda-Prutis, E.; Urban, J. (2009). The General Concept of Benchmarking and its Application in Higher Education in Europe. Higher Education in Europe, vol. 34, no. 3-4, pp. 497-510.

6. Woźnicki Jerzy [ed.]:Assumptions concerning development of management information system in HEIs (in polish). Polish Rectors Foundation (Monographs Series), Warszawa 2007

7. Woźnicki, Jerzy [ed.]: Benchmarking in Higher Education System (in polish).

8. Polish Rectors Foundation (Monographs Series), Warszawa 2008.

9. University of Sydney (2011). Benchmarking [online]; [available: 10.02.2011r.]. Retrieved from http://www.sydney.edu.au/learing/quality/benchmarking.shtml\#benchmarking.

10. University of Tasmania (2010). Report on the University Policy Benchmarking Project: Implications for the University of Tasmania, April, 2010 [online]; [available: 12.01.2011]. Retrieved from http://www.utas.edu.au/_data/assets/pdf_file/0003/42951/

11. Policy-Benchmarking-Project-Report.pdf.

12. Woźnicki, Jerzy [ed.]: Benchmarking in Higher Education System. Selected Problems (in polish). Polish Rectors Foundation (Monographs Series), Warszawa 2012

\section{BIOGRAPHICAL}

Professor, PhD, DSc in Electronics Engineering Since 1973 he has been working in Faculty of Electronics and Information Technology of Warsaw University of Technology where he passed by all levels of academic career from assistant to full professor. His scope of research activity covers electronics and the issues connected with knowledge society and knowledge based economy.

In the years 1996-2002 he was the Rector of the Warsaw University of Technology.

Until now he has performed the duties in many prestigious scientific organizations inter alia as the member of the Presidential Board of the Polish Section SPIE, Currently he is the President of the Polish Rectors Foundation and the Director of the Institute of Knowledge Society.

Mariusz Luterek, $\mathrm{PhD}$, is an associate professor at Warsaw University (Institute of Information Science and Book Studies). Since 2004 he closely works with Institute of Knowledge Society (IKS) and Polish Rectors Foundation (PRF), where he participated in many projects in the area of higher education, e.g. "Benchmarking in higher education", "Strategy for Development of Higher Education in Poland 2010-2020". Since 2012 he is Scientific Secretary at IKS.

Iryna Degtyarova, $\mathbf{P h D}$, is an associate professor at Oles Honchar Dnipropetrovsk National University (Faculty of Ukrainian and Foreign Philology and Study of Art), and a ViceChairman of Dnipropetrovsk Oblast Council of Young Scientists. Her scope of research activity covers linguistics and higher education policy in Ukraine and EU. Since 2012 she has closely worked with Polish Rectors Foundation (PRF), now she is a holder of PRF scientific scholarship. 